\title{
Reliability of MEMS accelerometers for instrumental intensity mapping of earthquakes
}

\author{
Gülüm Tanırcan ${ }^{1, *}$, Hakan Alçık ${ }^{1}$ and Kemal Beyen ${ }^{2}$ \\ ${ }^{1}$ Boğaziçi University, KOERI, Istanbul, Turkey \\ ${ }^{2}$ Kocaeli University, Izmit, Turkey
}

Article history

Received July 21, 2017; accepted November 21, 2017.

Subject classification:

Seismology; Instrument and techniques; Ground motion.

\begin{abstract}
This work investigates suitability of low cost Micro-Electro Mechanical System (MEMS) sensors in strong motion related studies, particularly in dense arrays utilized in producing quick shaking intensity maps. Two types of MEMS sensors (MEMS-5 and MEMS-50) and a reference sensor are tested under excitations of sweeping waves and scaled earthquake recordings. Transfer functions and correlation coefficients are compared. As for earthquake recordings, comparisons are carried out in terms of basic strong motion parameters and elastic response of structures that influences the design majors. The performance of the MEMS-50 sensor is also investigated on free field conditions. Different sensing characteristics are compared by performing time frequency analyses of small earthquake ground motion recordings of the MEMS-50 based accelerometer and of a co-located reference accelerometer. Test results show that the MEMS-50 sensor is able to record the mid-frequency dominant strong motion parameters with high correlation, where the high frequency components of the ground motion are underestimated. Such a difference in strong motion parameters on the other hand, does not manifest itself on empirical instrumental intensity estimations. Strong motion parameters from the reference and MEMS sensors converge to the same seismic intensity level. Hence a strong motion network with MEMS-50 sensors could be a modest option to produce peak ground velocity-based damage impact of an urban area under large-magnitude earthquake threats in the immediate vicinity. MEMS-5, which is an upper quality ensemble, is recommended for wide range of application including peak ground acceleration-based and peak ground velocity-based rapid shake maps.
\end{abstract}

\section{Introduction}

Seismic observation networks are key components of strong motion (SM) seismology. Small scale lateral variation of the strong ground motion, which might be produced by earthquake source or wave propagation characteristics, can be better detected by densely located networks. Real time data of those networks have been instantly used for quick magnitude and location determination. For earthquake early warning routines, the data is utilized to produce signals several seconds before the shear wave package shakes a region of interest. The data have also been used as supplements in loss estimation routines to improve the distribution of empirically derived peak ground motion parameters. While the necessity of such dense network in populated cities is inevitable, the high cost of the force-balance (FB) type accelerometer systems constitutes the biggest obstacle for dissemination.

Recent advances in sensor technology have helped the growth of local seismic networks. In recent years, many Micro-Electro Mechanical System (MEMS) based accelerometers have been successfully used in seismological and earthquake engineering projects. This is basically due to the increased precision obtained in these downsized instruments. Also, MEMS-based instruments are cheaper alternatives of FB type accelerometers. In the last two decades, numerous studies investigating seismic performance of various types of MEMS sensors have showed that these sensors are ad equate enough in terms of sensitivity, frequency response and amplitude responses [e.g. Evans et al. 2014 D'Alessandro and D'Anna 2013, Dashti et al. 2014]. MEMS-based accelerometers have a flat response in the frequency range $(0-10 \mathrm{~Hz})$ of earthquake engineering [Evans et al. 2014]. MEMS-based SM networks have been efficiently implemented in many projects around the world; for instance, Community Seismic Network [Clayton et al. 2011], Quake-Catcher Network [Cohran et al. 2009, 2011] and Self Organizing Seismic Early Warning Information Network [Fleming et al. 2009 , Bindi et al. 2015].

In Turkey, though MEMS-based accelerometers have been used in various individual applications such as magnitude and location determination of earth- 
quakes [AFAD 2017], structural health monitoring [Picozzi et al. 2009, Beyen et al. 2011], and earthquake early warning systems [Fleming et al. 2009], MEMSbased SM networks are not currently available in other populated and seismically active areas of the country, except Istanbul.

Motivation of this study comes from the fact that, since MEMS sensors are qualified to record SM parameters of large earthquakes, a dense network can be formed in an affordable price at highly populated areas. The goal of this study is to test the performance of MEMS sensors, which are available in the inventory of the Boğaziçi University, Kandilli Observatory and Earthquake Research Institute (KOERI), through shake table tests as well as free-field earthquake records. To this end, this study evaluates results of numerous tests performed at the shake table. It compares sweeping signals and scaled earthquake recordings of the MEMS sensors and of a reference sensor, in timefrequency domain. Similarly, the study also compares free field small magnitude earthquake recordings of a MEMS-50 sensor and a reference accelerometer, in time-frequency domain.

\section{Instrument Properties}

A special production MEMS-based SM accelerometer [AREL 2015] is used in the study; it is designed, produced and customized to complement the seismic network of KOERI for quick location \& magnitude determination [Erdik M. 2014 pers. comm.]. The accelerometer consists of two main parts: recording $\&$ digitizing block and wired application platform.
Analog to digital converter resolution is 24-bit. Sampling rate can be set up to $200 \mathrm{~Hz}$. The GSM modem and the power supply unit in the instrument are encapsulated by an aluminum case housing, and the internal GPS module in it has error free synchronization property.

Two accelerometers with two different types of MEMS sensors are used in the study. First type of sensor is STCLIS344ALH [ST Microelectronics 2008, 2017] (hereafter MEMS-50) sensors, each of which having a noise level of $50 \mu \mathrm{g}$ a dynamic range of $\pm 2 \mathrm{~g}$. Root mean square (RMS) noise of the sensors in 0.2 $30 \mathrm{~Hz}$ frequency band is expected to be between 0.10 $0.15 \mathrm{~cm} / \mathrm{s} 2$ [Havskov and Alguacil 2016]. Sensor belongs to a family of products suitable for a variety of applications including mobile terminals, gaming and virtual reality input devices, antitheft systems and inertial navigation, appliance and robotics [ST Microelectronics 2008, 2017]. The same sensors are known to be widely used for the structural health monitoring [Gattulli 2013, Potenza et al. 2015; Rice et al. 2010] and for earthquake early warning networks [Peng et al. 2013].

The second type of sensor is SD(C)1521 [Silicon Design 2017] (hereafter MEMS-5). It has a noise level of $5 \mu \mathrm{g}$. and a dynamic range of $\pm 2 \mathrm{~g}$. This accelerometer configuration was used for the MEMS-5 sensors in order to calculate loads and frequencies at renewed deck cables of the First Bosporus Suspension Bridge in Istanbul [Şafak E. 2016 pers. comm.]. Further properties of the digitizer and sensors are listed in Table 1.

\begin{tabular}{|c|c|c|}
\hline Sensor Name & ST C LIS344ALH & SD (C) Model 1521 \\
\hline ANSS classification & $\mathrm{C}$ & B \\
\hline Sensor Range & $\pm 2[\mathrm{~g}]$ & $\pm 2[\mathrm{~g}]$ \\
\hline Sensor Noise Density & $\leq 50\left[\mu \mathrm{g} /(\mathrm{Hz})^{1 / 2}\right]$ & $\leq 5\left[\mu \mathrm{g} /(\mathrm{Hz})^{1 / 2}\right]$ \\
\hline Supply Voltage (Vdd) & $\begin{array}{c}2.4-3.6[\mathrm{~V}] \\
\text { Typical = } 3.3[\mathrm{~V}]\end{array}$ & $\begin{array}{c}4.75-5.25[\mathrm{~V}] \\
\text { Typical }=5.0[\mathrm{~V}]\end{array}$ \\
\hline Sensitivity & $\mathrm{Vdd} / 5[\mathrm{~V} / \mathrm{g}]$ & $2000[\mathrm{mV} / \mathrm{g}]$ \\
\hline Non Linearity & $\pm 0.5[\% \mathrm{FS}]$ & 0.15 \\
\hline Cross-axis & $\pm 2[\%]$ & $2[\%]$ \\
\hline Frequency Response & - & $0-400[\mathrm{~Hz}]$ \\
\hline Operating Temperature Range & $-40-+85\left[{ }^{\circ} \mathrm{C}\right]$ & $-55-+125\left[{ }^{\circ} \mathrm{C}\right]$ \\
\hline
\end{tabular}

Digitizer Properties

ADC 24 Bit,

up to $200 \mathrm{~Hz}$ sampling rate data recording in miniSEED formats

Table 1. Comparison of techical specifications of sensors. 


\section{Evaluation of Instrument Performance}

\subsection{Shake table tests}

To evaluate the suitability of sensors in SM related studies, MEMS sensors and a reference sensor are tested under excitations of sweeping waves as well as scaled earthquake recordings. An electromagnetic uniaxial shaker with a testing capacity of $23 \mathrm{~kg}$ is used throughout the tests. It is $26 \mathrm{~cm} \mathrm{x} 28 \mathrm{~cm}$ in size with displacement range of 0 to $70 \mathrm{~mm}$. and frequency range of 0 to $25 \mathrm{~Hz}$. (Figure 1). Reference sensor on the table (hereafter Ref) is a Geosys company production, three-axis FB-type SSA320 model accelerometer [GeoWatch 1993]. It has a dynamic range of $\pm 2 \mathrm{~g}$. and flat response from DC up to $50 \mathrm{~Hz}$. It includes a 16 bit A/D converter. Sampling frequencies of all instruments are set to $200 \mathrm{~Hz}$.

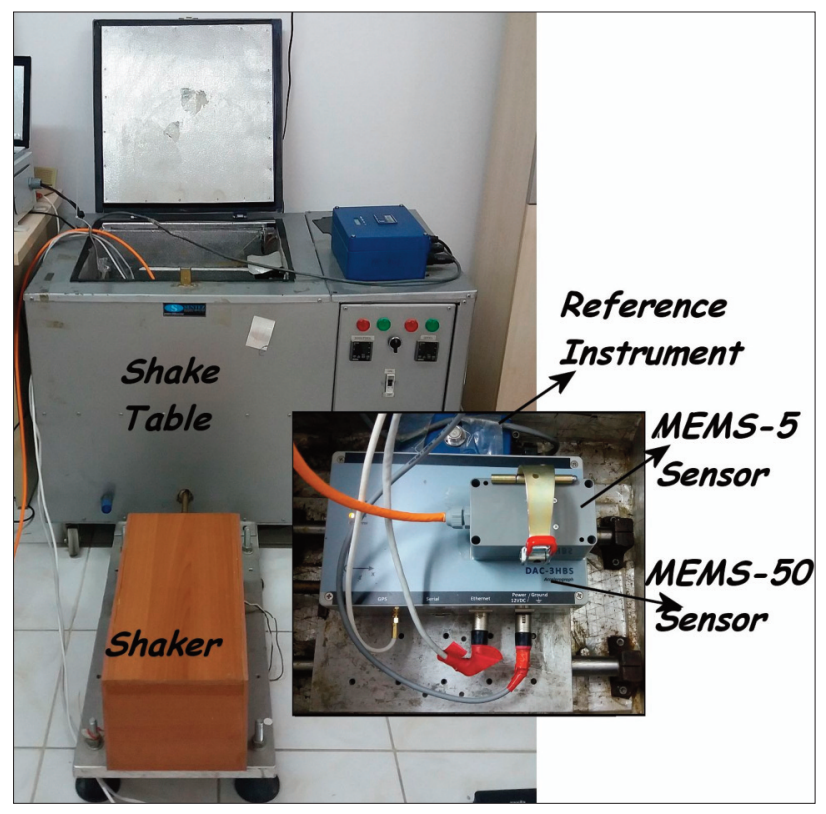

Figure 1. Electromagnetic uniaxial shaker and recorder. Internal view of shaker with SM accelerometer is seen at inlet photo.

Three sensors are co-mounted on the shake table. 45 tests in total were carried out using 35 second long sweeping signals. The response of the shaker below 1 $\mathrm{Hz}$ and/or the amplitudes smaller than $25 \mathrm{mg}$ were deemed not reliable, hence signals were allowed to have 9 discrete frequencies of $1,2,3,4,5,6,8,10$ and $12 \mathrm{~Hz}$. For each frequency, five tests were performed with amplitudes; 25, 50, 100, 200 and $400 \mathrm{mg}$.

The left panel in Figure 2 shows example acceleration recordings $(1 \mathrm{~Hz}-100 \mathrm{mg} ; 3 \mathrm{~Hz}-200 \mathrm{mg}$ and $10 \mathrm{~Hz}-$ $400 \mathrm{mg}$ ) of MEMS-5, MEMS-50 and Ref in time domain. Power Spectral Density Estimate (PSD) is also presented in the right panel. In general, PSD of MEMS decreases with increasing frequency. This reduction appears to be much sharper in MEMS-50. At $1 \mathrm{~Hz}$ central frequency, all signals and their PSD are almost identical. At $3 \mathrm{~Hz}$ central frequency, the PSD of MEMS-5 keeps following the traces of those of Ref; however, the PSD of MEMS-50 signal drops about $27 \%$. At $10 \mathrm{~Hz}$, the PSD of MEMS-50 drops drastically to very low values.

Root Mean Squared (RMS) response ratio in time domain and correlation coefficients (CC) of sweeping recordings are calculated to determine the level of similarity between MEMS based instruments and Ref. CC is defined as;

$$
C C=\frac{\operatorname{Cov}(X, Y)}{\sqrt{\sigma_{x} \sigma_{y}}}
$$

where $X$ and $Y$ are the recordings of the MEMS based instruments and Ref, respectively. Cov stands for covariance and $\sigma$ is standard deviation.

RMS amplitude with respect to frequency is shown in Figure 3 left column. For the MEMS-50, as the central frequency gets higher values, the RMS value decreases. The RMS amplitude ratio sharply falls from 1.0 to 0.4 as the frequency and amplitude increase. So the full amplitude cannot be recovered. The sensor response falls below $-3 \mathrm{~dB}$. in band limit (half power point) after $4.6 \mathrm{~Hz}$. and beyond this range, the signal is not considered as a usable output. Such behavior has been observed at similar tests performed with other low cost MEMS often used to control video games and defined by Evans et al. [2014] as "soft shoulder behavior". The MEMS-5, on the other hand, has almost flat response within the $1-12 \mathrm{~Hz}$ frequency range. Comparison of CC of MEMS based instruments and of Ref is also given in Figure 3 at central and right columns. In general, CC of both MEMS is above 0.9 for all of the tests, indicating a linear phase. It is also observed that CC of MEMS-50 quickly drops with increasing frequencies probably due to above mentioned soft shoulder behavior.

Sensors are also excited with three earthquake recordings. The suite of input earthquake is representative of the Central Marmara Fault passing through the Marmara Sea. Those are the 1999 Kocaeli Earthquake (Mw: 7.4) at SKR station NS component, IZT station EW component, and the 1978 Tabas Earthquake (Mw: 7.4) at TBS station, EW component. Recordings are scaled so as to fit to physical limits of the shake table. PGA of the scaled recordings of IZTEW, SKR-NS and TBS-EW are 0.22 g., 0.21 g. and 0.58 g., respectively. Figure 4 shows IZT-EW acceleration and velocity traces recorded by the MEMS-50, MEMS5 and Ref instruments. Signals are band-pass filtered (Butterworth filtering) between 0.1-10 Hz., which is the general frequency range of interest in earthquake en- 


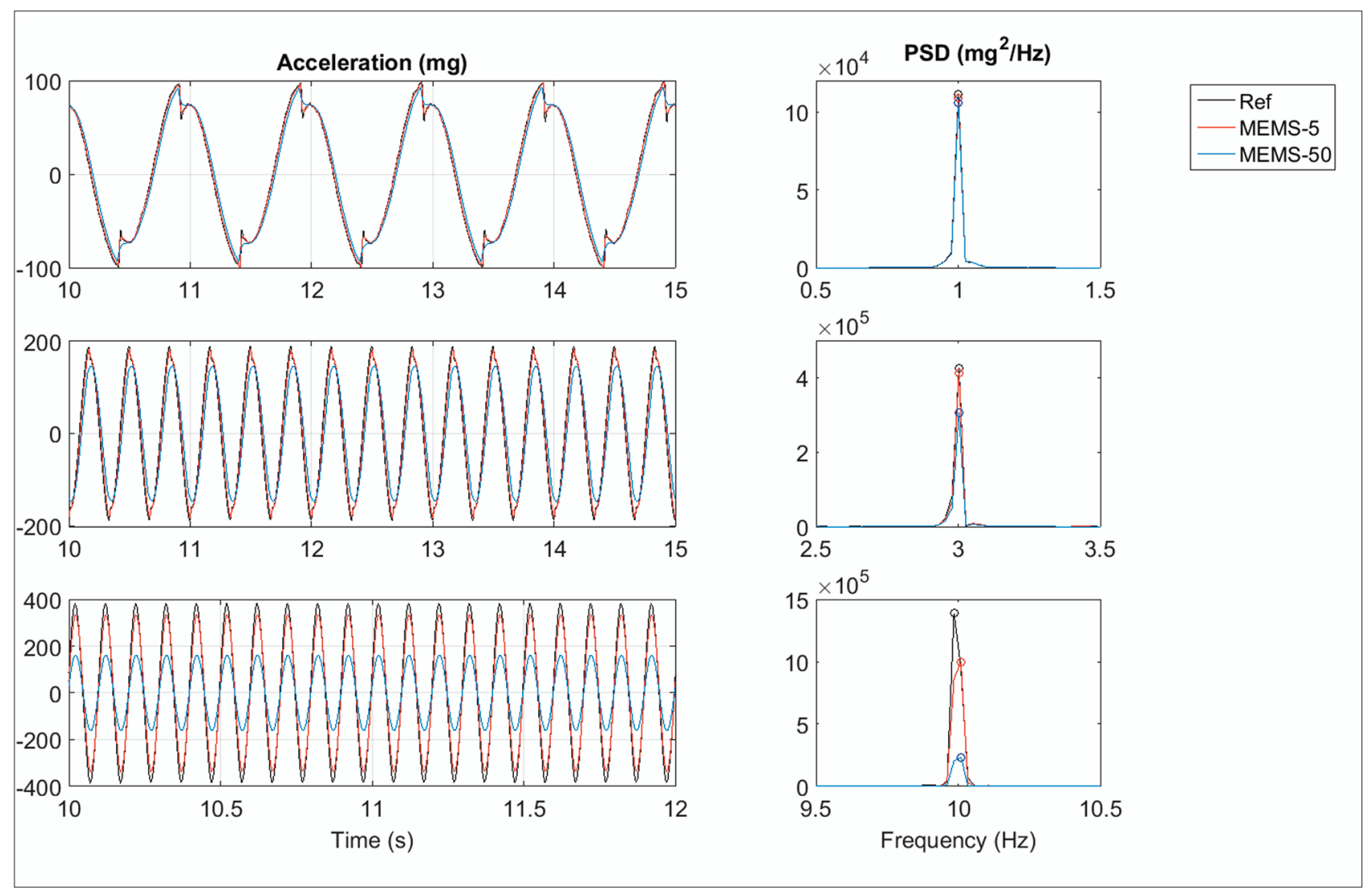

Figure 2. Sweeping signals recorded by the Ref (black), MEMS-50 (blue) and MEMS-5 (red) and their corresponding PSD: (top) 5s portion of the signal with a central frequency of $1 \mathrm{~Hz}$ and an average amplitude of $100 \mathrm{mg}$; (middle) $3 \mathrm{~s}$ portion of the signal with a central frequency of $3 \mathrm{~Hz}$ and average amplitude of $200 \mathrm{mg}$; (bottom) 1-sec portion of the signal with a central frequency of $10 \mathrm{~Hz}$ and average amplitude of $400 \mathrm{mg}$.

gineering, for comparison purposes. In laboratory condition, scaled earthquake recordings of MEMS and Ref have fairly good phase matchings in time and frequency domain. The CC of velocity traces recorded by the MEMS-5 and Ref is 0.99 . The CC only drops $3 \%$ for velocity traces recorded by the MEMS-50 and Ref. Welch PSD of the MEMS-50 and Ref, the MEMS- 5 and Ref are found to be almost identical in all frequency ranges. It is worth noting that, performance of the MEMS-50 under earthquake excitation is quite high. Such a high correlation could not be obtained during the test with sweeping signals. This may be due to the fact that in- struments are forced to record discrete amplitude levels at discrete frequencies during the test with sweeping signals. On the other hand peak amplitudes of the earthquake signals do not always arrive at high frequency band where MEMS-50 cannot recover. Hence $\mathrm{CC}$ and RMS values of the earthquake recordings are higher than those of sweeping signals.

Among several strong ground motion (SM) parameters; Peak Ground Acceleration (PGA), Peak Ground Velocity (PGV), Arias Intensity (AI), Cumulative Absolute Velocity (CAV) and 5\% damped Spectral Acceleration (Sa) values of recordings are compared for
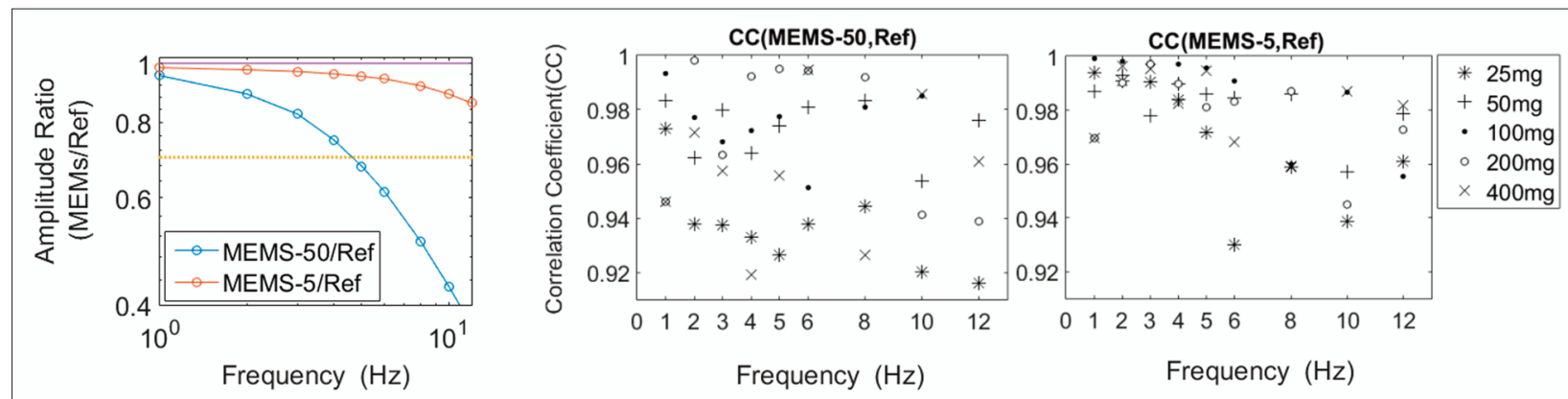

Figure 3. Variation in RMS amplitude ratios of MEMS-50/Ref and of MEMS-5/Ref with changing frequency and amplitudes is given in the left panel. Correlation coefficient (CC) distributions of MEMS-5 vs Ref and MEMS-50 vs Ref are presented in middle and right panel, respectively. 


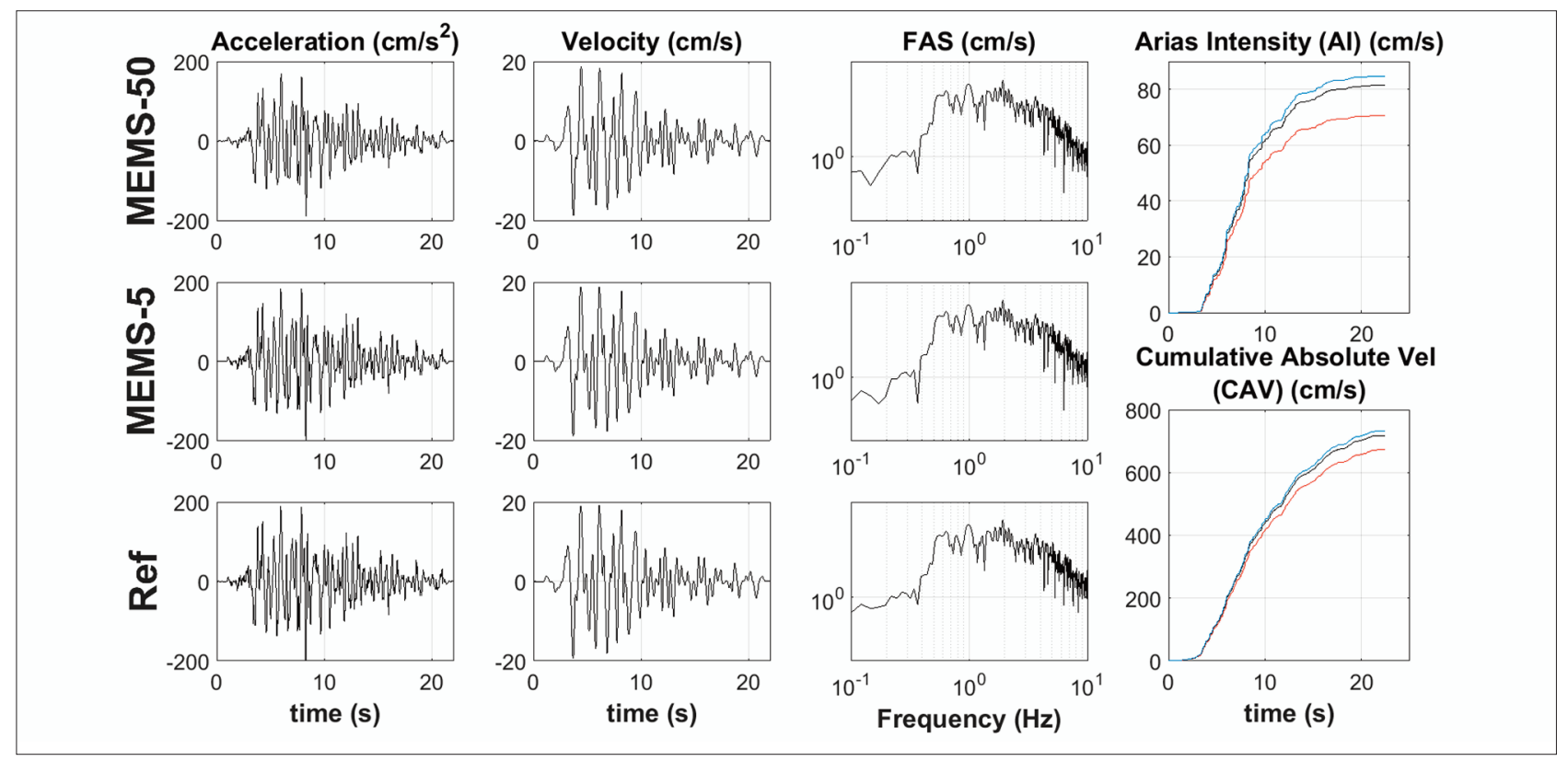

Figure 4. The 1999 Kocaeli Earthquake, IZT station, EW component recordings, (IZT-EW) acceleration and velocity traces recorded by MEMS-50 (red) and MEMS-5 (black) and Ref (blue) instruments with their corresponding AI and CAV values. Signals are band-pass filtered between $0.1-10 \mathrm{~Hz}$ for comparison purposes.

evaluation. The ratio of the SM parameters of the Ref and the MEMS which are given in Table 2 are all larger than $80 \%$. The MEMS-50 has a tendency to underestimate the SM parameters. PGV and CAV values of the MEMS-50 recordings are on average $10 \%$ lower than those of Ref recordings. This value increases to $20 \%$,
MEMS instruments and Ref are given in Figure 5. It portrays underestimation of acceleration (PGA and Sa) at structural periods less than $0.5 \mathrm{~s}$., which is probably due to the high frequency limits of the MEMS-50 instrument. Beyond $0.5 \mathrm{~s}$. underestimation of the $\mathrm{Sa}$ is equal or less than $10 \%$. The largest relative difference

\begin{tabular}{|c|c|c|c|c|c|c|c|}
\hline Earthquake & $\begin{array}{c}\text { Recording } \\
\text { Station-Component }\end{array}$ & $\begin{array}{c}\text { Ratio } \\
\text { (MEMS/Ref) }\end{array}$ & PGA (\%) & PGV (\%) & AI (\%) & CAV $(\%)$ & $\begin{array}{c}\text { MMI } \\
\text { (Tselentis and } \\
\text { Danciu, 2008) }\end{array}$ \\
\hline \multirow{6}{*}{$\begin{array}{l}1999 \text { Mw: } 7.4 \\
\text { Kocaeli Earthquake }\end{array}$} & \multirow{3}{*}{ IZT-EW } & MEMS-50 & 85 & 97 & 83 & 91 & \multirow{3}{*}{ VII (6.8-7.0) } \\
\hline & & & & & & & \\
\hline & & MEMS-5 & 97 & 97 & 83 & 91 & \\
\hline & \multirow{3}{*}{ SKR-NS } & MEMS-50 & 88 & 94 & 80 & 89 & \multirow{3}{*}{$\mathrm{VI}(5.8-6.0)$} \\
\hline & & & & & & & \\
\hline & & MEMS-5 & 98 & 98 & 96 & 98 & \\
\hline \multirow{3}{*}{$\begin{array}{l}1978 \text { Mw:7.4 } \\
\text { Tabas Earthquake }\end{array}$} & \multirow{3}{*}{ TBS-EW } & MEMS-50 & 85 & 93 & 83 & 91 & \multirow{3}{*}{ VI (6.4-6.5) } \\
\hline & & & & & & & \\
\hline & & MEMS-5 & 97 & 98 & 96 & 98 & \\
\hline
\end{tabular}

Table 2. Ratio of Strong Motion (SM) parameters calculated from Ref and MEMS (MEMS-50 and MEMS-5) scaled earthquake recordings.

when PGA and AI parameters are compared. AI and CAV graph of the IZT-EW recording in Figure 4 depicts this typical behavior. SM parameters of MEMS- 5 recordings and that of Ref recordings have almost identical values. These percentages are good indicators that SM parameters can be recorded with accuracy during large earthquakes.

Ratio of $5 \%$ damped acceleration response spectra $(\mathrm{Sa})$ calculated with earthquake recordings of between elastic response amplitudes is $40 \%$ at periods between 0.1-0.2 s. For the MEMS-5, deviation of Sa from that of Ref is only limited to $5 \%$.

3.2 Performance of the MEMS-50 under small earthquake excitation

Performance of the MEMS-50 is also investigated on the free field conditions. Considering the high seismic activity on Central Marmara Fault, a pilot network 

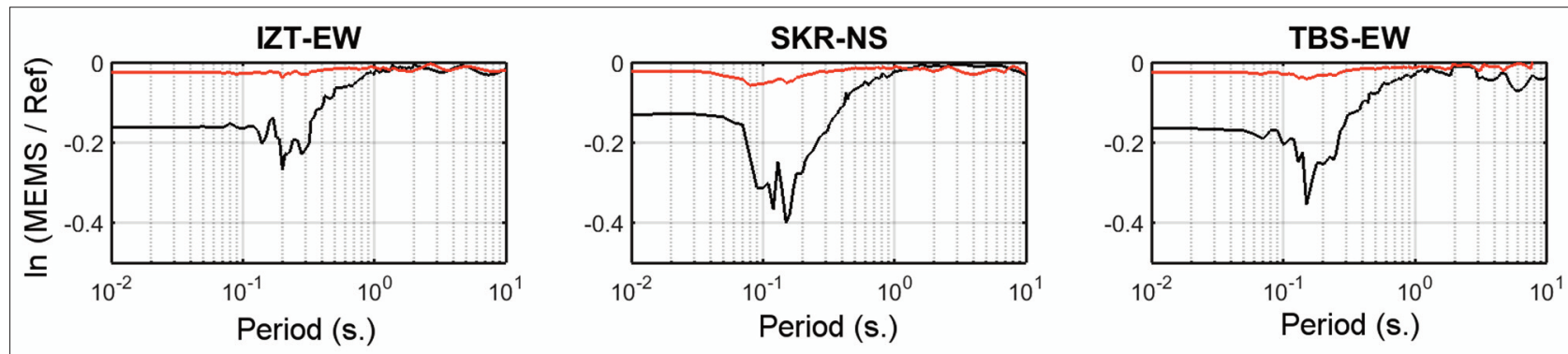

Figure 5. Comparison of 5\% damped spectral acceleration (Sa) ratios of the MEMS-50 (black) and MEMS-5 (red) instruments.

of three MEMS-50 accelerometers (stations; PBM, SKI and DSI) was set up at Tekirdağ city center, at the shore of northern Marmara Sea. All sensors were deployed at the basement level of one story government buildings. Distance between two farthest stations is $8 \mathrm{~km}$. Raw data are transmitted to a central server in real time through wireless internet. Customized in-house software is available to calculate the SM parameters of desired length of real time data [Tanircan et al. 2017]. Recording station, DSI, also houses an FB type tri-axial SM accelerometer (Tokyo Sokushin Co. Ltd, model CV-374A2) [Tokyo Sokushin 2017] (hereafter Ref-2). In a six month period, instruments recorded several small size earthquakes the largest of which occurred with a local magnitude (ML) of 4.5 on 28.10 .2015 at $24.5 \mathrm{~km}$ away from DSI station (Table 3).
Recording performances of the collocated MEMS50 accelerometer and Ref- 2 are compared for the ML 4.5 earthquake. Figure 6 presents the acceleration time histories of the MEMS-50 and the Ref- 2 as well as their corresponding Fourier Amplitude spectrum (FAS). Acceleration traces of both of the horizontal components have a fairly close matching in time domain, and equal practical significance. Their Fourier Amplitudes in the range of $0.9 \mathrm{~Hz}$. and $15 \mathrm{~Hz}$. also follow each other closely but Fourier amplitudes of the MEM-50 are slightly smaller than those of Ref- 2 at frequencies higher than $5 \mathrm{~Hz}$. Data sets are also examined to see time-varying correlation as a function of frequency in terms of wavelet based coherence. Data have maxima around 1 (i.e., nearly perfect agreement) between 1-10 $\mathrm{Hz}$ in the first 10-second time window, where the main

\begin{tabular}{|c|c|c|c|c|c|c|}
\hline $\begin{array}{l}\text { Earthquake } \\
\text { Date/Time (UTC) }\end{array}$ & $\begin{array}{l}\text { Location Lat. (N) } \\
\text { Lon. (E) }\end{array}$ & $\mathbf{M}_{\mathrm{L}}$ & Repi (km) & $\begin{array}{c}\text { PGA }(\text { EW/NS }) \\
\text { MEMS-50 }\end{array}$ & $\begin{array}{c}\text { PGA }(\text { EW /NS }) \\
\text { Ref-2 }\end{array}$ & Coherence of Acc. \\
\hline 28.10 .2015 16:20:02 & $40.82 / 27.76$ & 4.5 & 24.25 & $4.78 / 5.43$ & $6.59 / 7.62$ & $\begin{array}{c}0.88<(\mathrm{f}<2 \mathrm{~Hz}) \\
1.00(2 \mathrm{~Hz}<\mathrm{f}<10 \mathrm{~Hz})\end{array}$ \\
\hline
\end{tabular}

Table 3. 28.10.2015 ML4.5 earthquake information .PGA values and coherence of MEMS-50 and Ref-2 recordings at DSI station are also given.

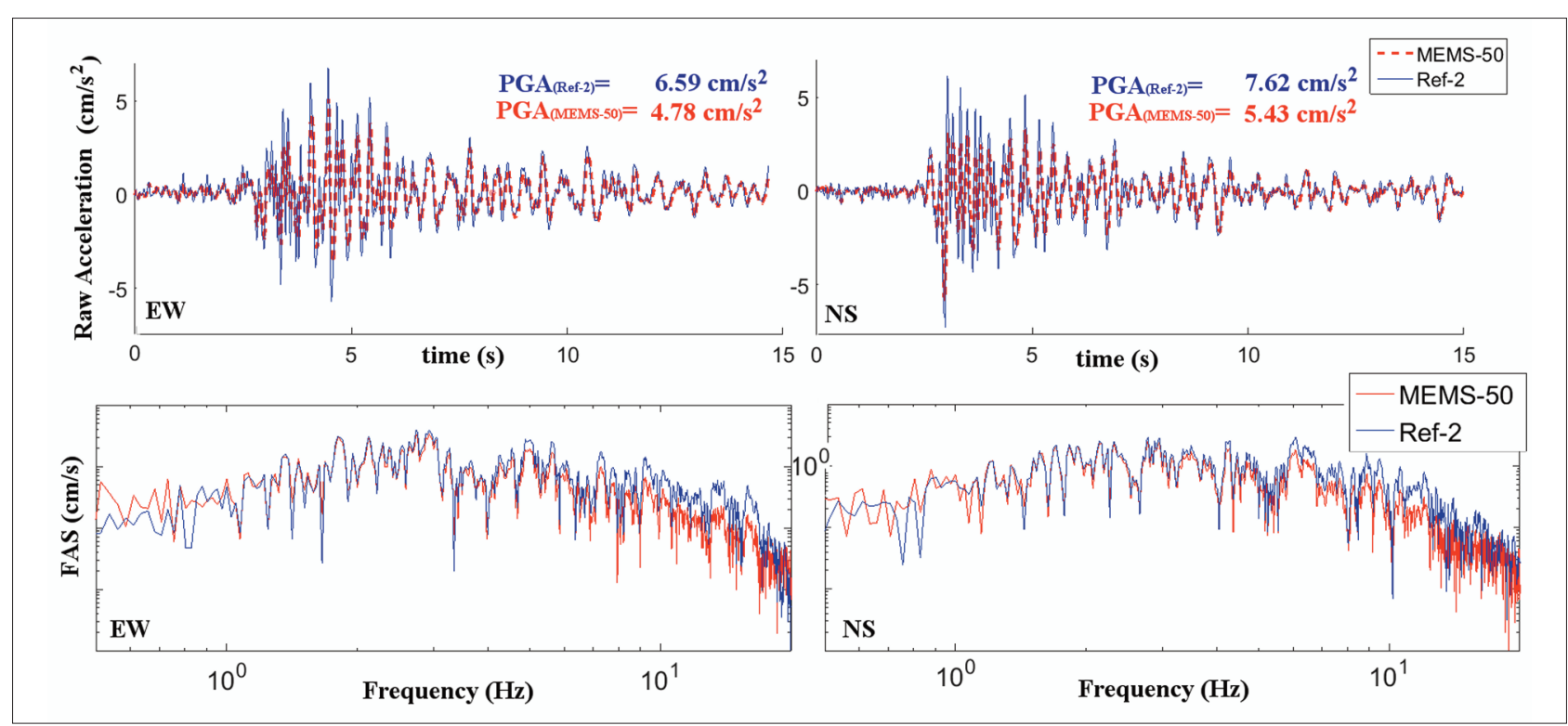

Figure 6. (top) Raw Acceleration Time histories of NS and EW components of the 28.10.2015 (ML:4.5) earthquake at the DSI station and (bottom) their Fourier Amplitude Spectra (FAS). 


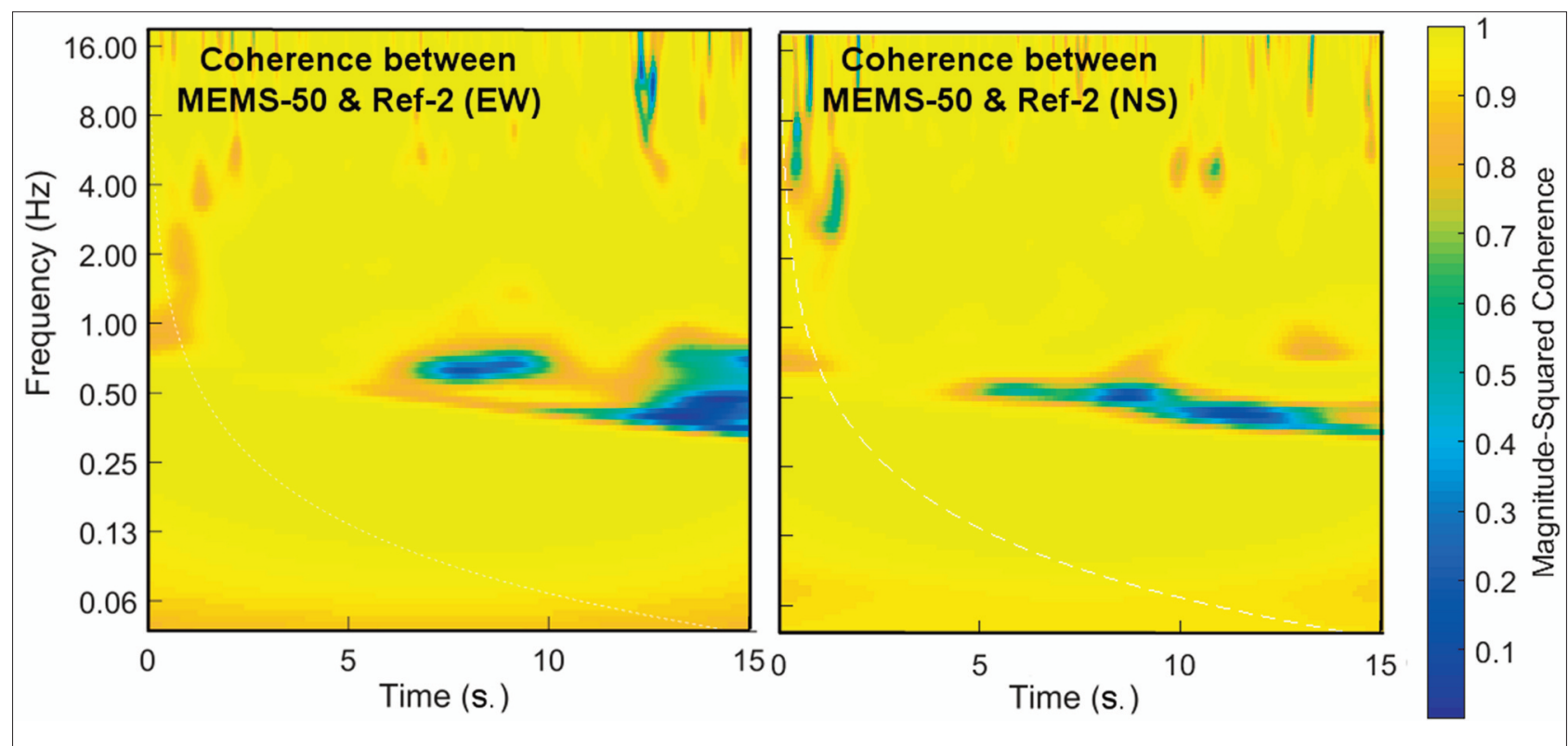

Figure 7. Coherences of the 28.10.2015 $\left(\mathrm{M}_{\mathrm{L}}: 4.5\right)$ earthquake recordings of MEMS-50 and Ref-2 at the DSI station.
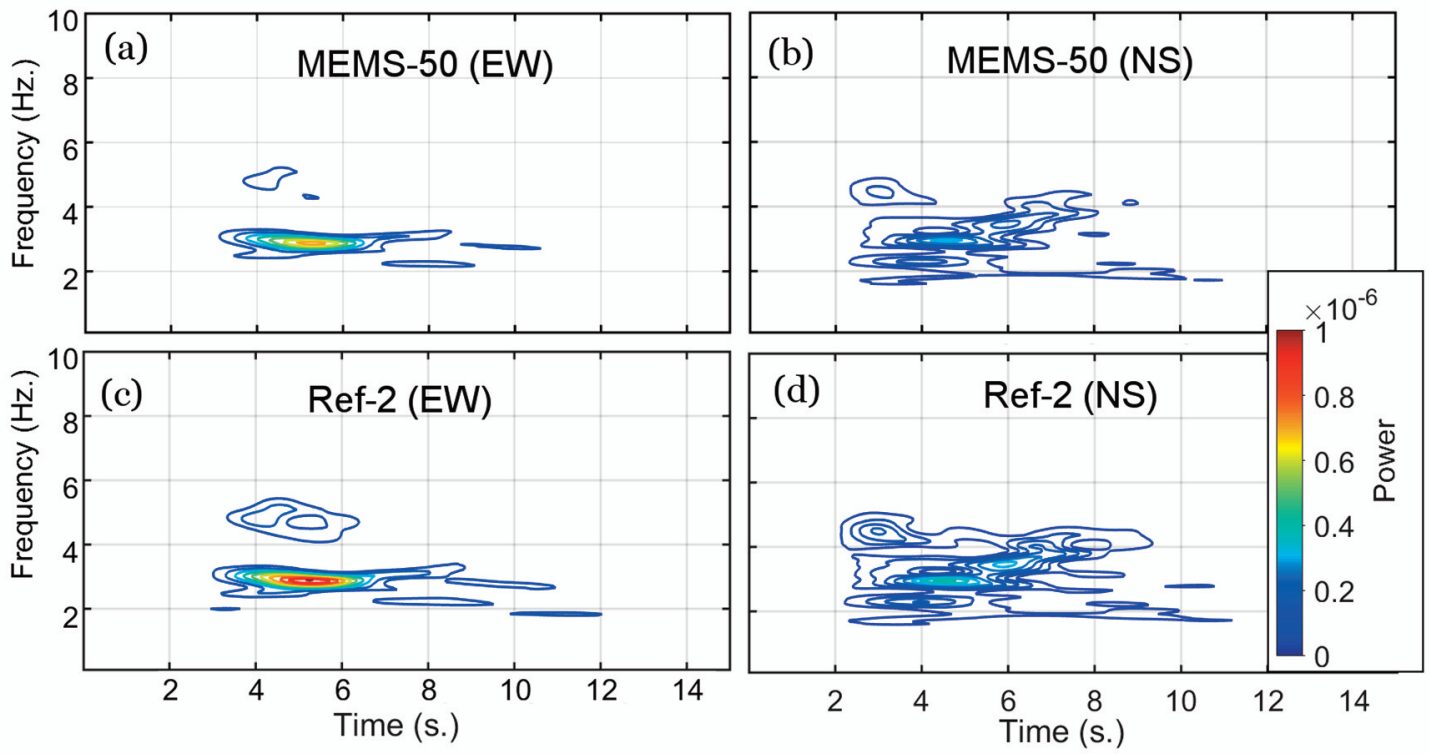

Figure 8. Continuous wavelet transform coefficient distribution of the 28.10.2015 ( $\left.\mathrm{M}_{\mathrm{L}}: 4.5\right)$ earthquake recordings at the DSI station. Wavelet powers of (a) MEMS-50 EW component (b) MEMS-50 NS components (c) Ref-2 EW component (d) Ref-2 NS component are given as contour maps.

S-wave energy packet arrives, for the both directions as seen in Figure 7. The coherence is weak at frequencies lower than $1 . \mathrm{Hz}$., probably due to existence of longperiod noise in the signal.

A comparative work is also investigated for the earthquake on the free field condition to show the capabilities of the sensor in Time-Frequency (T-F) domain. Continuous wavelet transform (CWT) coefficient distribution in T-F domain for horizontal components of the ML 4.5 earthquake are plotted for MEMS-50 and the Ref-2 in Figure 8. In the T-F spectra, between the time band of 0-15 s. and the frequency band of 1-10 Hz., wavelet coefficient peaks show very close tendency. Peaks are reaching their maxima at the same instant time and instant frequency. It is observed that the MEMS-50 is consistent with Ref- 2 very well in the time window of $0-15 \mathrm{~s}$. and in the frequency window of $1-10 \mathrm{~Hz}$.

The ambient and earthquake recordings of the ML:4.5 event are also used to seek instrument noise range. PSD of a MEMS-50 recordings and that of Ref2 were calculated using 5 -min. portion of noise recordings. PSD of MEMS-50 shows a downward trend between $-20 \mathrm{~dB}$ and $-40 \mathrm{~dB}$ band range, which are higher than seismic noise level defined by Peterson [1993]. It is, on the other hand, above the PSD of the 


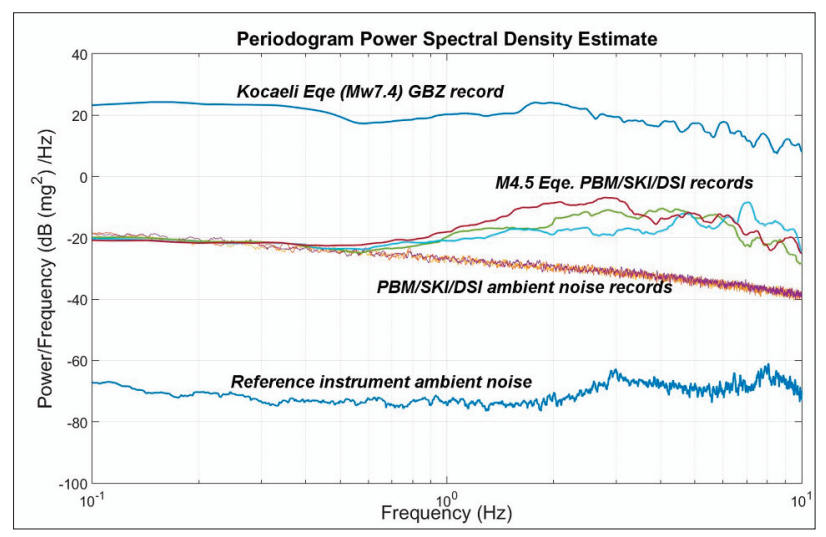

Figure 9. PSD determined from ambient noise at Tekirdağ DSI, PBM and SKI stations from MEMS-50 and Ref- 2 instruments. PSD of the 1999 Kocaeli Earthquake (Mw:7.4) GBZ recordings and the 28.10.2015 $\left(\mathrm{M}_{\mathrm{L}}: 4.5\right)$ Earthquake DSI, PBM and SKI recordings were also given in the figure for comparison.

ML:4.5 event at frequencies lower than $0.7 \mathrm{~Hz}$., implying that recordings of small size earthquakes are noise contaminated at low frequency (Figure 9). Waveforms from the 1999 Kocaeli Earthquake (Mw7.4) at near field GBZ station were also given. Comparing the PSDs of the Kocaeli event and that of MEMS-50 instrument, it can be assumed that the self-noise of MEMS-50 instrument is low enough to record large size earthquakes.

\section{Conclusion and discussion}

In this study, functionality of two types of MEMS sensors has been investigated through shake table tests. A reference FB instrument was used for comparison purposes. Tests with sweeping signals show that after 4. $6 \mathrm{~Hz}$., amplitudes of the MEMS-50 sensor recordings are not reliable. The MEMS- 5 sensor on the other hand, has better performance with a maximum $10 \%$ underestimation of amplitude ratio in 1-10 Hz. frequency band.

Both the MEMS-50 and MEMS-5 sensors underestimate SM parameters when they are shaken with M7+ earthquake excitations; underestimation of the MEMS5 is at a negligible level, though. Performance of the MEMS-50 under earthquake excitation is quite high when it is compared to the test with sweeping signals. While, the MEMS-50 cannot fully reproduce the high frequency dominant SM parameters, i.e. PGA and AI, it better records the mid-frequency dominant SM parameters, i.e. PGV and CAV. Such difference in strong motion parameters, on the other hand does not manifest itself on intensity estimations. The PGV and CAV values of recordings of all accelerometers (MEMS and FB) converge to the same intensity level (Table 2).

A small magnitude event recorded by the MEMS50 supports the aforementioned findings. While there are some variations in peak amplitude values at high frequency, it is intensely seen from the coherence spectra in T-F domain that the performance of the MEMS50 has high common power practically in a linear fashion with the Ref-2 reference sensor. Hence, data from a network comprised of MEMS-50's could be used to extract spatial variability in ground motion at the frequency range of interest in earthquake engineering.

It has been known that PGV is the major indicative parameter of damage at high intensity levels (IMMI $>$ VII) [Wald et al. 1999, 2010]. Recent research results are in line with these findings. Structural damage criteria (e.g. roof displacement) correlate better with PGV than PGA [Lesueur et al. 2013, Wu et al. 2003] particularly for midrise reinforced concrete structures [Perrault and Geuguen 2015]. In addition, CAV is the recommended measures for rapid damage assessment tools like shake maps [Tselentis and Danciu 2008]. Considering those facts it can be deduced that a network with the MEMS-50 could be a modest option to produce a PGV-based damage impact of an urban area under large magnitude earthquake threats in immediate vicinity. MEMS-5, which is an upper quality ensemble, is recommended for wide range of application including PGA and PGV based rapid shake $\&$ damage maps.

Cost effectiveness is an important issue to enable widespread deployment of accelerometers. In general, the imported value of sensors are in the range of 50 USD, 750 USD and 2500 USD for MEMS-50, MEMS-5 and a well-known force-balance type, respectively.

Average price of a fully equipped domestic accelerometer station with MEMS-50 sensor is around 2000 USD. This price increases up 50\% if a MEMS-5 sensor is utilized. A FB type accelerometer is at least 3 times more expensive than an accelerometer with a sensor that has similar quality with the MEMS-5. Hence, an MEMS-50 accelerometer station is approximately $30 \%$ and $80 \%$ cheaper than an accelerometer stations with upper quality ensemble and well-known FB type accelerometers, respectively. We hope that this study helps to clarify the trade-off between the quality and the cost of the MEMS- based accelerometers.

In this study laboratory tests are performed only with one ensemble of MEMS sensors. It is beneficial to test each axes of several representative MEMS sensors, (particularly the cheapest sensor, MEMS-50) on a shake table in a future study. Confidence interval ranges of amplitudes may be decided based on responses of individual sensors. The insight gained from these analyses is expected to be useful for getting information about the differentiation of performances of low cost sensors. 
Acknowledgements. We thank to shake table laboratory personnel of KOERI for performing tests and instrument deployment at Tekirdağ. We are also grateful to Sevim Avcı Yener from Tekirdağ Metropolitan Municipality for getting station deployment permission from related authorities as well as for providing technical personnel, logistic and equipment. Strong motion recordings of the Ref-2 at DSI station were provided by Dr. Oğuz Özel within the SATREPS -MarDIM project. Very fruitful and constructive comments from two anonymous reviewers improved the quality of the manuscript. This study was supported by Boğaziçi University Scientific Research Project Funds. Project \#9340/14TP4. Any use of trade, firm or product names is for descriptive purposes only and does not imply endorsement by the authors.

\section{References}

AFAD (2017). http://kyh.deprem.gov.tr/?aspxerrorpath $=/$ ftpt.htm

AREL (2015). http: / / www.areldeprem.com.tr/.

Beyen, K., M. Kutanis, H. Ö. Tanöz and D. Başkan (2011).Wireless Sensors' Network with Intelligent Transmission Protocol for Structural Health Monitoring and Structural Identification, 7th National Conference on Earthquake Engineering, 30 May-3 June 2011, Istanbul, Turkey (in Turkish).

Bindi, D., T. Boxberger, S. Orunbaev, M. Pilz, J. Stankiewicz, M. Pittore, I. Iervolino, E. Ellguth and S. Parolai (2015). On-site early-warning system for Bishkek (Kyrgyzstan), Annals of Geophysics. No58,1.

Clayton, R. W., T. Heaton, M. Chandy, A. Krause, M. Kohler, J. Bunn, R. Guy, M. Olson, M. Faulkner, M. H. Cheng, L. Strand, R. Chandy, D. Obenshain, A. Liu and M. Aivazis (2011). Community Seismic Network, Annals of Geophysics, 54 (6),738-747.

Cochran, E. S., J. F. Lawrence, C. Christensen and R. S. Jakka (2009). The Quake-Catcher Network: Citizen Science Expanding Seismic Horizons. Seismological Research Letters, 80(1), 26-30.

Cochran E. S., J. F. Lawrence, A. Kaiser, B. Fry, A. Chung and C. Christensen (2011). Comparison between low-cost and traditional MEMS accelerometers: a case study from the M7.1 Darfield, New Zealand, aftershock deployment, Annals of Geophysics Vol 54, No 6.

D’Alessandro A. and G. D’Anna (2013).Suitability of low-cost three-axis MEMS accelerometers in strongmotion seismology: Tests on the LIS331DLH (iPhone) accelerometer. Bulletin of the Seismological Society of America 103 (5), 2906-2913.

Dashti S.,J.D.Bray,J.Reilly,S.Glaser,A.Bayen and E.Mari (2014).Evaluating the Reliability of Phones as seismic Monitoring Instruments, Earthquake Spectra,
V30, 2 721-742.

Evans, J. R., R. M. Allen, A. I. Chung, E. S. Cochran, R. Guy, M. Hellweg and J. F. Lawrence (2014). Performance of Several Low-Cost Accelerometers. Seismological Research Letters, 85(1).

Fleming, K., M. Picozzi, C. Milkereit, F. Küehnlenz, B. Lichtblau, J. Fischer, C. Zulfikar, O. Özel, and The SAFER and EDIM working groups (2009). The SelfOrganizing Seismic Early Warning Information Network (SOSEWIN), Seismol. Res. Lett. 80, no. 5, 755-771.

Gattulli, V. (2013). Advanced Applications in the Field of Structural Control and Health Monitoring After the 2009 L'Aquila Earthquake, Engineering Seismology, Geotechnical and Structural Earthquake Engineering book edited by Sebastiano D’Amico. ISBN 978-953-51-1038-5, March 20.

GeoWatch (1993). Strategic Alliance between Terra and Geosys. Geophysical measuring solutions. issue no.3, November, https://www.geosig.com/getnewsfile.aspx?newsid=99 (accessed in June 2017).

GeoSIG (2017). https://www.geosig.com/searchresults.aspx (accessed in June 2017).

Havskov, J.and G.Alguacil (2016). Instrumentation in Earthquake Seismology. Second edition, Springer.

Lesueur C, M. Cara, O. Scotti, A. Schlup and C. Sira (2013). Linking ground motion measurements and macroseismic observations in France: a case study based on accelerometric and macroseismic databases. Journal of Seismology, 17, 313-333.

Peng, C., X. Zhu, J. Yang, B. Xue and Y. Chen (2013). Development of an integrated on site earthquake early warning system and test deployment in Zhaotong, China, Computers Geosciences, 56, 170-177.

Perrault, M. and P. Gueguen (2015). Correlation between ground notion and building response using California earthquake records. Earthquake Spectra, 31(4), 2027-2046.

Peterson, J. (1993). Observations and Modelling of Seismic Background Noise. U.S. Geological Survey OpenFile Report 93-322, Albuquerque, New Mexico.

Picozzi, M., C. Milkereit, C. Zulfikar, K. Fleming, R. Ditommaso, M. Erdik, J. Zschau, J. Fischer, E. Safak, O. Özel, and N. Apaydin (2009).Wireless technologies for the monitoring of strategic civil infrastructures: An ambient vibration test on the Fatih Sultan Mehmet Suspension Bridge in Istanbul, Turkey, Bull. Earthquake Eng. 8, no. 3, 671-691.

Potenza, F., F. Federici, M. Lepidi, V. Gattulli, F. Graziosi and A.Colarieti (2015). Long term structural monitoring of the damaged Basilica S.Maria di Collemag gio through a low cost wireless sensor network, 
J.Civil Struct Health Monit., 5-5, 655-676.

Rice, J. A., K. Mechitov, S. H. Sim, T. Nagayama, S. Jang, R. Kim, B. F. Jr. Spencer, G. Agha and Y.Fujino (2010). Flexible smart sensor framework for autonomous structural health monitoring, Smart Structures and Systems, 6 (5-6), 423-438.

Silicon Design. (2017). https: / / www.silicondesigns.com/datasheets (accessed in June 2017).

ST Microelectronics (2008). LIS344ALH 3-axes MEMS Inertial Sensor, high performance 3 -axis $\pm 2 / \pm 6 \mathrm{~g}$ ultra compact linear accelerometer, Technical document April 2008 Rev.3, Geneva, Switzerland.

Tanircan G., Y. Kaya and H. Alçık (2017). A low Cost Accelerometer Network for Generation of Shake Maps, 16th World Conference on Earthquake Engineering. No1744, Santiago, Chile.

Tselentis, G.A. and L. Danciu (2008). Empirical Relationships between Modified Mercalli Intensity and Engineering Ground-Motion Parameters in Greece, Bulletin of the Seismological Society of America, 98(4), 1863-1875.

Tokyo Sokushin (2017). http:/ / www.to-soku.co.jp/en/products/memory/index.html (accessed in June 2017).

Wald, D. J., V. Quitoriano, T. H. Heaton, and H. Kanamori (1999). Relationships between peak ground acceleration, peak ground velocity, and modified Mercalli intensity in California, Earthquake Spectra 15, 557-564.

Wald, D.J., K.S. Jaiswal, K.D. Marano, D.B. Bausch and M.G. Hearne (2010). PAGER-Rapid assessment of an earthquake's impact. U.S. Geological Survey Fact Sheet 2010-3036, Revised November.

Wu, Y. M., T. L. Teng, T. C. Shin and N. C. Hsiao, (2003). Relationship between peak ground acceleration, peak ground velocity, and intensity in Taiwan, Bulletin of the Seismological Society of America, 93, 386-396.

\footnotetext{
*Corresponding author: Gülüm Tanırcan, Boğaziçi University, KOERI, Istanbul, Turkey; email: birgore@boun.edu.tr.

C) 2017 by the Istituto Nazionale di Geofisica e Vulcanologia. All rights reserved.
} 